\title{
Carbon dioxide gas leaks during transanal minimally invasive surgery
}

\author{
M. F. Khan ${ }^{1,2} \cdot$ R. A. Cahill ${ }^{1,2}$ \\ Received: 31 May 2020 / Accepted: 23 June 2020 / Published online: 7 July 2020 \\ (c) Springer Nature Switzerland AG 2020
}

Transanal minimally invasive surgery (TAMIS) and transanal total mesorectal excision (TaTME) are mostly performed using a dedicated access device, namely the Gelpoint Path (Applied Medical, Rancho Santa Margarita, CA, USA). The instability or oscillation of the rectal wall due to variance in pneumorectal distension that frustrated early adopters has been addressed by addition of high flow insufflation systems (e.g. Airslea, Conmed, Milford, CT USA) [1] and, more recently, with an insufflation stablization bag (Applied Medical) [2]. By adding consistency of intrarectal gas volume, these greatly improve precision and fluency in intraand transrectal surgery.

The fundamental cause of rectal billowing is often considered to be carbon dioxide $\left(\mathrm{CO}_{2}\right)$ flow proximally out of the rectum into the colon. $\mathrm{CO}_{2}$ leakage out of the patient is also possible via the valved access trocars, the Gelseal Cap application or around the access channel. The emergence of coronavirus disease 19 (COVID-19) has focused attention on aerosol risk associated with minimally invasive surgery (MIS), including TaTME [3], especially since pathogen particles have been identified in the stool of infected patients [4].

In this video, we use a sensitive near-infrared optical imaging system specifically attuned to $\mathrm{CO}_{2}$ detection (FLIR GF 343, FLIR Systems, Ltd, United Kingdom) to dynamically assess for gas effluvium during TAMIS (see video). As seen in the video, $\mathrm{CO}_{2}$ escapes from the trocar valves with each instrument entry and exit, with the valves becoming increasing leaky as the procedure continues. Interestingly,

Electronic supplementary material The online version of this article (https://doi.org/10.1007/s10151-020-02284-9) contains supplementary material, which is available to authorized users.

R. A. Cahill

ronan.cahill@ucd.ie

1 UCD Centre for Precision Surgery, School of Medicine, University College Dublin, Dublin, Ireland

2 Department of Surgery, Mater Misericordiae University Hospital, Dublin, Ireland episodic belching of gas via the Gelseal Cap application site occurs intermittently throughout the case, seemingly unrelated to instrument exertion or torque. These leaks occur with or without the associated use of an Airseal device (notably this device itself acts as a chimney for intrarectal gas escape and room air entrainment during suctioning) [5].

Although transmission of COVID-19 via gas aerosolised at MIS has not been proven, we present this video to demonstrate previously undocumented mechanisms of gas escape from the patient into the room during TAMIS procedures. The faces of surgeons are closer to this anorectal gas effluvium at TAMIS and TATME, than is the case with colonoscopy indicating the importance of wearing appropriate personal protective equipment during, and continuing perhaps after, the current pandemic.

Acknowledgements The authors gratefully acknowledge the efforts of Mr David Doyle, Butler Technologies, Ireland and Mr Steve Beynon, FLIR Systems Ltd, United Kingdom in making available a FLIR GF 343 thermographic camera for the purposes of this assessment.

\section{Compliance with ethical standards}

Conflict of interest $\mathrm{RC}$ is named on a patent filed in relation to processes for visual determination of tissue biology and receives speaker fees from Stryker Corp, consultant fees from Touch Surgery and Distal Motion and research funding from Intuitive Corp and with IBM.

Ethical approval All procedures were in accordance with the ethical standard of the Institutional Research Committee (Mater Misericordiae University Hospital) and were approved by the hospital in advance including specific consent from the patient participants. Procedures were performed in accordance with the ethical standards as laid down in the 1964 Declaration of Helsinki and its later amendments or comparable ethical standards.

Informed consent No personal identification is included the in the video or manuscript and so the patient has given consent for this recording for teaching/medical research and so fits this requirement. 


\section{References}

1. Nicholson G, Knol J, Houben B, Cunningham C, Ashraf S, Hompes R (2015) Optimal dissection for transanal total mesorectal excision using modified $\mathrm{CO}_{2}$ insufflation and smoke extraction. Colorectal Dis 17(11):O265-O267. https://doi.org/10.1111/ codi.13074

2. Waheed A, Miles A, Kelly J, Monson JRT, Motl JS, Albert M (2017) Insufflation stabilization bag (ISB): a cost-effective approach for stable pneumorectum using a modified $\mathrm{CO}(2)$ insufflation reservoir for TAMIS and taTME. Tech Coloproctol 21(11):897-900. https://doi.org/10.1007/s10151-017-1716-7. [Epub2017Nov14.PMID:29139046]

3. Lacy AM, De Lacy FB, Balibrea JM (2020) Considerations for transanal total mesorectal excision (TaTME) use during the COVID-19 pandemic. Br J Surg 107(7):e203. https://doi. org/10.1002/bjs.11685.[Epub2020May8.PMID:32383490]

4. Gu J, Han B, Wang J (2020) COVID-19: Gastrointestinal Manifestations and Potential Fecal-Oral Transmission. Gastroenterology 158(6):1518-1519. https://doi.org/10.1053/j.gastro.2020.02.054. [Epub2020Mar3.PMID:32142785]

5. Dalli J, Khan MF, Nolan K, Cahill RA (2020) Laparoscopic pneumoperitoneum escape and contamination during surgery. Colorectal Dis 12:148-316

Publisher's Note Springer Nature remains neutral with regard to jurisdictional claims in published maps and institutional affiliations. 